OPEN ACCESS

Edited by:

Mariagrazia Di Giuseppe,

University of Pisa, Italy

Reviewed by:

Elisabeth Punzi,

University of Gothenburg, Sweden

Mario Miniati,

University of Pisa, Italy

*Correspondence:

Emanuele Maria Merlo

emerlo@unime.it

Specialty section:

This article was submitted to

Psychopathology,

a section of the journal

Frontiers in Psychology

Received: 08 March 2021

Accepted: 08 April 2021

Published: 20 May 2021

Citation:

Merlo EM, Stoian AP, Motofei IG and Settineri S (2021) The Role of Suppression and the Maintenance

of Euthymia in Clinical Settings.

Front. Psychol. 12:677811.

doi: 10.3389/fpsyg.2021.677811

\section{The Role of Suppression and the Maintenance of Euthymia in Clinical Settings}

\author{
Emanuele Maria Merlo ${ }^{1 *}$, Anca Pantea Stoian ${ }^{2,3}$, Ion G. Motofei ${ }^{2}$ and Salvatore Settineri ${ }^{4}$ \\ 'Department of Adult and Childhood Human Pathology "Gaetano Barresi," University of Messina, Messina, Italy, ${ }^{2}$ Carol \\ Davila University of Medicine and Pharmacy, Bucharest, Romania, ${ }^{3}$ National Institute of Diabetes, Nutrition and Metabolic \\ Diseases "N. C. Paulescu," Bucharest, Romania, ${ }^{4}$ Department of Biomedical and Dental Sciences and Morphofunctional \\ Imaging, University of Messina, Messina, Italy
}

Background: Defense mechanisms serve as mediators referred to the subjects' attempt to manage stressors capable of threatening their integrity. Mature defense mechanisms represent the high adaptive group, including suppression, which allows the subject to distance disturbing contents from consciousness. In line with general defensive intents, suppression would preserve stable mood states, as in the case of euthymia. Clinical issues usually disturb homeorhesis, so that the study of subjects' suppressive tendencies would suggest possible existing relations among defense mechanisms, mood states, and clinical issues. The study highlighted the significant existing relations among factors such as suppression, euthymia, mood states, and clinical psychological phenomena.

Methods: The observation group was composed of 150 participants, 51 males (34\%) and 99 females (66\%), aged from 25 to 30 years old, with a mean age of 26.63 years old ( $S D=1.51)$. The study was conducted through the use of measures related to subjects' characteristics, euthymia, psychological flexibility and psychological well-being (Euthymia Scale), suppression (Suppression Mental Questionnaire), well-being (Who-5), and compassion (ProQol-5).

Results: The performed analyses consisted of descriptive statistics, correlations, differences, and regressions among the considered variables. Starting from the first hypothesis, SMQ factors appeared to be significantly and positively correlated with Euthymia factors, rather than Regression in the Ego service (-). In line with the previous result, significant and positive correlations emerged among SMQ and Well-being (WHO-5) variables, maintaining an inverse relation with Regression in the Ego service. Significant differences emerged between male and female groups concerning SMQ total score and rationalization, with higher male group scores. Finally, significant dependencies emerged among the selected predictors (SMQ variables) and Compassion satisfaction.

Conclusion: The emerged results highlighted significant relations among the considered variables so that it was possible to highlight the common directions assumed 
by suppression variables, well-being, and euthymia. Moreover, suppression appeared as a significant predictor with a causal role in clinical satisfaction. The results that have emerged allow us to consider defenses through an empirical perspective, useful to suggest an extension to other groups, phenomena, and conditions.

Keywords: clinical psychology, defense mechanisms, emotional distress, euthymia, suppression

\section{INTRODUCTION}

The maintenance of a stable mood can be influenced by different factors, including defense mechanisms whose role can be understood starting from classical contributions due to Sigmund Freud's efforts. In these terms, the concept of a defense mechanism has appeared since 1894, regarding the origin of hysteric symptomatology and manifestations. Some relevant contributions treated the defense mechanisms referring to their origins, impact on clinical practice, and future directions. In line with Vaillant's (1992) perspective, the theme of defense mechanisms can be considered as historically directed to modern methods, directed to the fields of clinical practice. Defense mechanisms can be considered as predominantly unconscious. Their use can refer to specific psychopathological domains, although their appearance is strongly linked to the subject's developmental stages. According to Anna Freud (1936), their use can be considered as reversible, strictly linked to subject's structure and environmental conditions.

Current research considers the possibility of involving defense mechanisms in empirical terms. It is always more fruitful to deal with high validity instruments adherent to classical contributions and new perspectives. In 1994, APA defined the defense mechanisms as unconscious operations, whose role is linked to protecting the individual from thoughts, feelings, internal, or external conflicts. This definition respects the theme of defense, since its use is strongly related to the use of defenses in avoiding conflicts properly referred to internal/external stressful issues. The anguish derived from these types of disputes puts the subject in a condition useful to react, depending on structure.

The research on defense mechanisms allowed Vaillant (1977) to propose a hierarchical model considering defenses organized at different levels so that archaic defenses were distinguished from neurotic and high adaptive/mature defenses. Different levels were provided and involved in developing empirical instruments useful to compare theoretical issues to research, clinical practice, and future possibilities (Perry and Henry, 2004).

As suggested by recent research (Di Giuseppe et al., 2020a), the effort to develop valid instruments was referred both to clinical and healthy populations, so that it would be possible to keep the transversal relevance of defenses (Merlo et al., 2021). In literature, many studies expressed the need to extend the study of defensive patterns to different clinical conditions and developmental stages (Di Riso et al., 2015; Di Giuseppe et al., 2019; Gugliandolo et al., 2020). The stressors' incidence on the onset of lesions and functional maladjustment, can derive from specific psychological factors (Lingiardi et al., 2010; Perry et al., 2015; Porcerelli et al., 2017; Gangemi et al., 2018; Catalano et al., 2019; Conversano, 2019; Fiegl et al., 2019; Kelly et al., 2019; Martino et al., 2019, 2020a,b,c; Merlo, 2019; Vita et al., 2020). Clearly, the possibility to obtain data from research studies dedicated to the mentioned themes took place through the efforts to operationalize the theoretical basis, constructing empirical instruments, as in the case of Perry's DMRS (Perry's1990; Di Giuseppe et al., 2020b), of Bond's DSQ-40 (Bond et al., 1983; Farma and Cortinovis, 2000; Perry and Bond, 2012) and other valuable instruments.

In these terms, according to Berney et al. (2014), clinical and empirical aspects of defense mechanisms provide knowledge about affective dynamics and tendencies occurring in all individuals, both clinical and non-clinical populations. In their hierarchical organization, defense mechanisms present different features, so that archaic defenses differ from neurotic and adaptive ones. Vaillant (1994) therefore introduced humor, sublimation, suppression, altruism, and anticipation in the IV category, respectively, named mature defenses. In terms of adaptive tendencies and dynamics, repression has been considered as a high adaptive defense (Metzger, 2014), included among mature defenses and considered by Vaillant as follows: "When used effectively [.] suppression is analogous to a well-trimmed sail" (2000, p.94). Suppression can be considered as a predominantly conscious defense mechanism, whose use is close to the subject's conscious need to avoid disturbing contents. Although the role of this defense can be considered as similar to repression, this last represents a predominantly unconscious dynamic. The main difference between these two defense mechanisms is based on the level of subject's consciousness during the use of the defenses. Through suppression, the individual overcomes internal/external issues, replacing the disturbing contents with more adaptive themes and tasks.

When considering the role of defense mechanisms in avoiding anguish and maladjustment, it is fundamental to mention what can be regarded as directly deriving from their adaptive or excessive use. Affective dynamics result as indirectly involved but still present. In these terms, although defense mechanisms act in the regard to affectivity and representations, their role does not disappear. Most of the psychosomatic issues in fact represent the final stage of excessive defensive tendencies. Beside displacing disturbing contents from consciousness, regressions to fantasy are often included (Kris and Kaplan, 1952; Kris, 1952a,b,c; Knafo, 2002) defined this tendency as "Regression in the Service of the Ego," in order to describe short regressions useful to avoid anguish and to manage representations without reality limits. Thus, empirical research demonstrated how alexithymia does not correspond to the absence of emotions, rather than in a lack of mentalization. Some concepts tend to attract more attention depending on literature trends, but understanding basic phenomena producing comprehensive 
definitions is fundamental (as in the case of resilience and wellbeing). Over the years, the concept of well-being has undergone numerous changes and extensions that have led to a broader and more complete vision of the term, no longer focused on the absence of pathologies, suffering, or discomfort, but on a condition of balance between the person and the environment. Connected to this construct is the concept of euthymia.

In the psychiatric literature, the term euthymia essentially indicates the lack of significant distress. In psychology, "euthymia" shows the typical mood of the non-depressed individual, who experiences a serene or neutral mood. In clinical settings, euthymia is often defined only in negative terms as the absence of symptoms related to mood, neglecting the positive aspects of curing. In 1958, psychologist Marie Jahoda created a model of psychological well-being made up of various dimensions, such as regulating behavior (internal), environmental control, satisfying and positive relationships with others, and the degree of personal growth, self-realization, and self-acceptance.

Jahoda also underlines a characteristic linked to the concept of euthymia: "integration," a balance of psychic forces that corresponds to the concept of "psychological flexibility," an ability useful to maintain individual balance and resist stress (greater resilience and tolerance to frustration). Based on these terms, some research contributions offered the possibility to operationalize the concepts in order to reach empirical validity and reliable instruments. Starting from these concepts, (Guidi and Fava, 2020; Fava and Bech, 2016) pointed out that the purpose of clinical evaluation is to explore the presence of positive affectivity, psychological well-being, and their interactions with the course of symptoms. To analyze these features in an integrative way, a clinimetric perspective is necessary.

The term clinimetric indicates an area interested in measuring clinical problems with no place in the standard clinical taxonomy. These problems include types, severity and sequence of symptoms, disease progression rate (staging), severity of the comorbidity, functional capacity problems, reasons for medical decisions (e.g., therapeutic choices), and many other aspects of daily life, such as well-being and distress. Directly related to this path, several research contributions arose from the commitment to measure empirically clinical issues through a cinimetric perspective (Carrozzino et al., 2019; Guidi and Fava, 2021), with a look toward well-being, psychopathology and psychotherapy (Fava et al., 2017).

Considering the figures mentioned above, we stated four hypotheses to highlight common directions, differences, and dependencies among the included phenomena (alexithymia, well-being, suppression, and compassion). In detail, the following paragraph describes the relationships and implications of potential variables.

\section{The Current Study}

Four hypotheses were stated in order to allow the relations to emerge according to the methodology.
Hypothesis 1: We hypothesize that suppression assumes similar directions with euthymia. In particular, we hypothesize positive correlations with euthymia, rather than Regression in the Ego service.

Hypothesis 2: We hypothesize coherent directions assumed by suppression and well-being, except for Regression in the Ego service.

Hypothesis 3: We hypothesize significant differences between male and female groups concerning Euthymia, Suppression, and Well-being.

Hypothesis 4: We hypothesize the existence of significant dependencies among suppression variables and clinical commitment variables, highlighting the causal role of suppression linked to adaptation.

\section{MATERIALS AND METHODS}

\section{Procedure and Participants}

The observation group consisted of 150 healthy participants, 51 males (34\%) and 99 females (66\%). The age of the participants included in the study was between 25 and 30 years old, with a mean age of 26.63 years old $(\mathrm{SD}=1.51)$. The research was carried out at the University of Messina, Italy with the aim of exploring clinical psychological issues strictly related to clinical practice. All participants were involved in clinical assistance.

Every participant fully completed the questionnaires, including information regarding their activities, studies, gender, and age. Each participant fully completed a checklist referred to health status, in order to be considered admissible for the final group. Health subjects were selected in order to complete the questionnaire. The checklist was both referred to psychological and physical domains. The compilation of the questionnaires was an online form due to the current COVID-19 pandemic.

Before adhering to informed consent, each participant was informed about the anonymous nature of the methods of data processing, as required by the procedures of the ethical committee evidenced by the approval (University of Messina COSPECS Ethical Committee, Ethical committee number: COSPECS_14_2020).

\section{Statistical Analysis}

The data were expressed as a mean and a standard deviation, and the categorical variables as number and percentage.

According to the study hypotheses, the "Spearman test" was applied to evaluate the correlations among variables of the following instruments.

The Student's $t$ test compared gender groups, referring to euthymia, well-being, and suppression.

Multivariate linear regression was used to assess each of the ProQol clinical outcomes' dependence on a set of independent predictors (SMQ Total Score and related factors).

Statistical analyses were performed using SPSS 26.0 for the Window package.

A $P$ value smaller than 0.050 was considered to be statistically significant. 


\section{Instruments}

\section{Suppression Mental Questionnaire}

The Suppression Mental Questionnaire (Settineri et al., 2019a,b) consists of 18 items assessing the use of the mature defense mechanism named suppression, based on a five-point Likert scale. SMQ is a self-report instrument validated in both paperand-pencil and app version, whose validation highlighted the existence of three main factors, namely, Repressive function, Regression in the service of the Ego, and Rationalization.

According to classical literature, suppression is meant as the capacity to banish disturbing contents from consciousness. This capacity is related to a consistent, conscious effort, useful to let the subject direct his/her resources toward adaptive activities avoiding anguish deriving from disturbing contents.

The validation of the instrument showed good sampling adequacy (K.M.O. = 0.648) and the following Cronbach coefficients: Repressive function $=0.742$; Regression in the service of the Ego $=0.804$; Rationalization $=0.698$. In order to describe the inner structure of the instrument, the following items appeared as belonging, respectively, to each factor: Repressive function composed by items $3,4,7,8,10,14,15,16,17$, and 18; Regression in the service of the Ego, items 5, 6, 9, 11, and 12; Rationalization, items $1,2,7$, and 13. In line with the paperand-pencil version, the instrument's app adaptation provided for the following alpha coefficients: $0.74-0.73$ for the first factor, $0.80-0.77$ for the second, and $0.70-0.76$ for the third one.

\section{WHO-5}

World Health Organization (Five) Well-being Index [World Health Organization (WHO), 1998], composed of five items assessing well-being, evaluated using a six-point Likert scale from 5 (always) to 0 (never). According to the validation study [World Health Organization (WHO), 1998] and with several other research items (Topp et al., 2015), the scale appeared as a valid instrument useful for assessing subjects' well-being. As a generic scale, its properties are related to the possibility to evaluate mental well-being through a limited number of items (Hall et al., 2011; Bech, 2012).

\section{Euthymia Scale}

Through their clinimetric analysis, Carrozzino et al. (2019) showed that a good definition for Euthymia (provided by Fava and Bech, 2016) has been considered as the preliminary step to build up a scale useful for the evaluation of the selected phenomenon. Fava and Bech (2016) incorporated Jahoda's definition of euthymia Jahoda's (1958) to develop a self-report rating scale named Euthymia Scale. In these terms, the purpose regarded the absence of affective disorders and the presence of psychological flexibility and resistance to stressors. Their clinimetric study, directly linked to this definition, provided two dimensions: Psychological flexibility and Psychological wellbeing. The analysis showed the scale's validity and its two dimensions through two main clinimetric parameters, known as scalability and incremental validity (respectively, assessed through Mokken and hierarchical linear regression analyses). The study on healthy subjects produced the following indexes, referred to Mokken analysis: 0.25 for the total score of the 10item Euthymia Scale, 0.28 for Psychological flexibility, and 0.30 for Psychological well-being.

\section{ProQol-5}

The Professional Quality of Life Scale (ProQol-5) is a self-report instrument dedicated to studying adaption and maladjustment deriving from clinical practice. The scale was validated by Stamm $(2005,2009)$ and adapted in Italian by Palestrini et al. in Palestrini et al., 2009. The scale consists of 30 items supported by a fivepoint Likert scale.

The factorial analysis showed three different factors, respectively, Compassion satisfaction, Burnout, and Secondary traumatic stress. Each factor consists, respectively of the following items: Factor 1, items 3, 6, 12, 16, 18, 20, 22, 24, 27, and 30; Factor 2, items $1^{*}, 4^{*}, 8,10,15^{*}, 17^{*}, 19,21,26$, and 29 (* for $^{*}$ inverted scores); Factor 3, items 2, 5, 7, 9, 11, 13, 14, 23, 25, and 28. Reliability indexes provided by the authors were as follows: Compassion Satisfaction, alpha scale reliability $=0.88$; Burnout, alpha scale reliability $=0.75$; Secondary traumatic stress, alpha scale reliability $=0.81$.

\section{RESULTS}

Descriptive statistics (mean and the standard deviation) are reported in Table $\mathbf{1}$ in order to highlight the presence of considered phenomena.

Hypothesis 1:

Hypothesis 1 (Table 2) concerned the directions assumed by the considered phenomena in correlational terms so that the factors of Euthymia and Suppression Questionnaire were involved. As it is possible to assume, according to the values reported in Table 2, all correlational relationships emerged among SMQ factors, Euthymia Scale Total Score, and Euthymia Scale Psychological Flexibility were significant. Six of the relationships, as mentioned earlier, emerged as significant and positive, two as significant and inverse. In detail, the positive relations were referred to Euthymia Total Score and Psychological Flexibility with SMQ Total Score, SMQ Repressive

TABLE 1 | Descriptive statistics for study variables.

\begin{tabular}{lcc}
\hline & Mean & Standard deviation \\
\hline Years of Study & 14.41 & 2.30 \\
Euthymia Scale & 6.70 & 2.19 \\
Euthymia Scale Psychological Flexibility & 3.58 & 1.22 \\
Euthymia Scale Psychological Well-Being & 3.12 & 1.43 \\
SMQ Total Score & 52.52 & 8.42 \\
SMQ Repressive function & 24.56 & 6.58 \\
SMQ Regression in the service of the Ego & 18.21 & 4.07 \\
SMQ Rationalization & 13.71 & 2.57 \\
WHO-5 & 14.34 & 4.02 \\
Compassion satisfaction & 39.84 & 5.41 \\
Burnout & 23.26 & 4.98 \\
Secondary traumatic scale & 23.90 & 6.05
\end{tabular}


TABLE 2 | Correlation coefficients among SMQ and Euthymia Scale variables.

\begin{tabular}{|c|c|c|c|}
\hline & $\begin{array}{l}\text { Euthymia } \\
\text { Scale Total } \\
\text { Score }\end{array}$ & $\begin{array}{l}\text { Euthymia } \\
\text { Scale } \\
\text { Psychological } \\
\text { Flexibility }\end{array}$ & $\begin{array}{c}\text { Euthymia } \\
\text { Scale } \\
\text { Psychological } \\
\text { Well-Being }\end{array}$ \\
\hline SMQ Total Score & $0.321^{\star \star}$ & $0.378^{\star *}$ & $0.187^{\star \star}$ \\
\hline $\begin{array}{l}\text { SMQ Repressive } \\
\text { function }\end{array}$ & $0.468^{\star \star}$ & $0.474^{\star *}$ & $0.315^{\star \star}$ \\
\hline $\begin{array}{l}\text { SMQ Regression in } \\
\text { the service of the Ego }\end{array}$ & $-0.238^{\star \star}$ & $-226^{\star \star}$ & -0.159 \\
\hline SMQ Rationalization & $0.297^{\star \star}$ & $0.432^{\star \star}$ & 0.110 \\
\hline
\end{tabular}

TABLE 3 | Correlation coefficients among SMQ and WHO-5 factors.

\begin{tabular}{|c|c|}
\hline & WHO-5 \\
\hline SMQ Total Score & $0.260^{\star \star}$ \\
\hline SMQ Repressive function & $0.365^{\star \star}$ \\
\hline SMQ Regression in the service of the Ego & $-0.181^{\star}$ \\
\hline SMQ Rationalization & 0.149 \\
\hline
\end{tabular}

TABLE 4 | Comparison between male and female groups.

\begin{tabular}{lccc}
\hline Variables & Male & Female & p value \\
\hline Euthymia Scale & $6.88 \pm 2.10$ & $6.61 \pm 2.24$ & 0.475 \\
SMQ Total score & $54.43 \pm 6.47$ & $51.54 \pm 9.14$ & $\mathbf{0 . 0 2 7}$ \\
SMQ Repressive function & $25.86 \pm 5.46$ & $23.88 \pm 7-02$ & 0.060 \\
SMQ Regression in the service of the Ego & $18.17 \pm 3.86$ & $18.23 \pm 4.20$ & 0.935 \\
SMQ Rationalization & $14.41 \pm 2.42$ & $13.35 \pm 2.58$ & $\mathbf{0 . 0 1 5 *}$ \\
WHO-5 & $14.82 \pm 3.66$ & $14.10 \pm 4.19$ & 0.279
\end{tabular}

${ }^{*} p<0.05$. Bold values were the significant values.

function, and SMQ Rationalization. In our perspective and line with the considered literature, Suppression appeared to assume the same direction of Euthymia, highlighting a positive relation. It is meant as a positive role deriving from mature defense and adaptation mechanisms, in line with classical studies and recent empirical research contributions. Suppression appeared to be correlated significantly and positively, confirming the role of high mature defenses on mood states.

Concerning Regression in the Ego service, it appeared to be significantly and inversely correlated to Euthymia Total Score and Psychological Flexibility showing as the regression to phantasies and phantasmatic atmospheres is closely related to archaic-type functioning built on the necessity to avoid reality limitations and lows. In compliance with the performed analyses, suppressive tendencies appeared as mainly directed to maintaining a stable mood. Concerning Psychological Well-Being (Euthymia Scale's second dimension), the two significant and positive relations that emerged were referred to SMQ Total Score and Repressive functions. In these terms, the significant correlations that emerged highlighted the directions assumed by the variables so that suppressive necessities showed a higher propensity to take the same direction of stable mood maintenance. In clinical terms, suppression had a crucial role in favoring the adaptation of the subjects. The correlational analysis provided for relevant significant relations, so that increasing suppressive tendencies corresponded to higher levels of euthymia. In terms of mood balance and adhering to classical and empirical literature, suppression demonstrated his adaptive direction.

Hypothesis 2:

Hypothesis 2 (Table 3) referred to the occurring relationships among suppressive tendencies and subjects' well-being. The used instruments provided for different factors involved. Correlational analyses were performed in order to highlight common directions among the considered phenomena, so that significant relations emerged among SMQ Total Score, SMQ Repressive function, SMQ Regression in the service of Ego, and WHO-5 Well-being scale. No significant association emerged regarding SMQ Rationalization.

Two of the three significant relations were positive, rather than SMQ Regression in the service of the Ego. No significant relation emerged concerning SMQ Rationalization. The first two significant and positive relations showed the same direction of suppressive tendencies and well-being, in line with previous results referred to euthymia.

Moreover, in the previous correlational analysis, Regression in the service of the Ego emerged significantly but inversely related to well-being. Generally, as for euthymia, the increase of wellbeing corresponded to the rise of suppression. This fact appears as confirmatory of the theoretical aspects of mature defense mechanisms. As emerged with reference to mood balance and euthymia, the increase of the suppressive tendency corresponded to higher scores in the well-being domain. This fact highlighted how in clinical terms defenses maintain their role, in this case with direct reference to adaptation.

Hypothesis 3:

Hypothesis 3 (Table 4) refers to the emergence of possible significant differences between the two groups, respectively, male and female subjects. The analysis performed through the Student's $t$ test involved parametric variables, meant as factors related to Euthymia, SMQ Total Score, Repressive function, Regression in the Ego service, Rationalization, and WHO5 well-being. Significant differences emerged regarding SMQ Total Score and Rationalization. Considering the highest mean scores, they were both referred to male groups, highlighting a greater score in the use of mature defense mechanisms such as Suppression, with rationalization tendencies.

\section{Hypothesis 4:}

Hypothesis 4 (Table 5) was aimed at highlighting the emergence of possible dependencies among the set of predictors, namely, SMQ Total Score, SMQ Repressive Function, SMQ Regression in the service of the Ego, SMQ Rationalization, and three dependent variables contained into ProQol-5 Scale, specifically Compassion satisfaction, Burnout, and Secondary traumatic stress. 
TABLE 5 | Multivariate linear regressions analysis.

\begin{tabular}{|c|c|c|c|c|c|c|c|c|}
\hline & \multicolumn{2}{|l|}{ SMQ Total Score } & \multicolumn{2}{|c|}{ Repressive function } & \multicolumn{2}{|c|}{ Regression in the service of the Ego } & \multicolumn{2}{|l|}{ Rationalization } \\
\hline & $\mathrm{B}(\mathrm{Cl})$ & $P$ & $\mathrm{~B}(\mathrm{Cl})$ & $P$ & $\mathrm{~B}(\mathrm{Cl})$ & $P$ & $\mathrm{~B}(\mathrm{Cl})$ & $P$ \\
\hline Compassion satisfaction & $-1.90(-3.36 ;-0.438)$ & $0.011^{*}$ & $2.07(0.661 ; 3.49)$ & $0.004^{\star}$ & $2.13(0.680 ; 3.59)$ & $0.004^{\star}$ & $1.36(0.109 ; 2.63)$ & $0.033^{*}$ \\
\hline Burnout & $1.11(-0.260 ; 2.48)$ & 0.112 & $-1.22(-2.55 ; 0.105)$ & 0.071 & $-0.857(-2.22 ; 0.511)$ & 0.218 & $-0.857(-2.01 ; 0.511)$ & 0.165 \\
\hline Secondary traumatic stress & $-0.902(-2.51 ; 0.710)$ & 0.271 & $0.720(-0.843 ;-2.28)$ & 0.364 & $1.36(-0.244 ; 2.97)$ & 0.096 & $0.691(-696 ; 2.07)$ & 0.326 \\
\hline
\end{tabular}

$B=$ Beta coefficient; $\mathrm{Cl}=$ confidence Interval; ${ }^{*} \mathrm{P}<0.05$ was considered as significant for the multivariate linear regression analyses.

The significant dependencies were referred to Compassion satisfaction, with reference to the whole set of independent variables.

The emerged dependence relationships highlighted the role of defensive paths on clinical commitment in terms of the usefulness of high adaptive defenses. In particular, repression appeared as directly responsible for SMQ factors' increase.

These data have placed the present findings in line with previously performed analyses and research, referring to the employment of defense mechanisms to reach an adaptive tendency and stable object relations in clinical terms. Finally, in clinical terms, the high adaptive role of suppression took place with direct reference to causal relations. In the current study, suppression assumed coherent directions with mood balance and well-being. In causal terms, suppression demonstrated to directly influence clinical satisfaction.

\section{DISCUSSION}

The present study highlighted the existing relations among relevant phenomena such as defense mechanisms, mood states, and clinical issues. In particular, the study hypotheses included the abovementioned phenomena in order to study their directions, differences, and dependence relations.

Starting from the considered defense mechanism, suppression emerged as a consistent way to manage internal/external stressors, as in the case of adaptation, pathological psychosomatic issues, and medical conditions due to psychological phenomena (Warnes, 1982; Cramer, 2000; De Burge, 2001; Szwec, 2018; Settineri et al., 2019a; Conversano et al., 2020b; Conversano and Di Giuseppe, 2021).

In particular, the first statistical analysis was performed regarding the existing relations among suppression and euthymia, explaining significant associations. The protective role of suppression appeared as linked to euthymia, so that higher levels of suppression corresponded to higher scores related to euthymia. Therefore, suppression represents a conscious dynamic steaming from of the need to remove disturbing contents from cognition. We are aware of this fact in the subject's attempts to reach adaptation, where personal facts, representations, and adverse affectivity are spaced out in order to pursue tasks. Distress arising from inappropriate emotions, feelings, and images is thus avoided by the mechanism of suppression.

The significant and positive relations were referred to general terms (meant as suppressive functioning) and strictly related factors. In opposite terms, regression to fantasy emerged aversive instead of the maintenance of positive mood and affective stability.

The link between defensive structure, coping, and mood regulation appears more and more precise, directly supported by recent literature (Brockman et al., 2017; Compas et al., 2017; Schäfer et al., 2017; Weissman et al., 2019). The need to avoid unsatisfying and adverse consequences due to representations and emotions accounts for one of the main themes in defenses. In these terms, our study described a continuity with previously emerged studies.

As a consequence of this emerged result, well-being appeared as significantly associated with suppression. Even in this case, Regression in the service of the Ego occurred as significantly and inversely directed. In most of the classical works, it appeared as mainly related to creativity and action, close to fantasies and regressive moves (Wild, 1965; Fitzgerald, 1966; Bush, 1969; Knafo, 2002), in our case far from rational and adaptive behaviors tending to consider needs strictly related to reality.

In our experience, the suppressive tendency was shown as the adaptation process stems as strong as directed to adjustment. Higher levels were detected in male subjects, referring to the emerged significant differences, statistically performed in our analysis.

Recent literature highlighted how subject structures influence the course of cure (Eglinton and Chung, 2011; Lomas et al., 2019; Conversano et al., 2020a; Kinsella et al., 2020), with particular reference to compassion (McNally et al., 2019; Merlo et al., 2020a,b).

In our results, dependence relations emerged concerning compassion satisfaction and all suppression factors. Even in this case, the significant dependences highlighted the role of suppression with reference to the opportunity to experience compassionate clinical circumstances (Zeidner et al., 2013; Ivicic and Motta, 2017; Singh et al., 2020). The role of compassion is currently emerging as a high influencing factor, both related to clinicians and patients and extended to several conditions such as psychopathology, therapy, mental health, image concerns, neurovegetative phenomena, and general health outcomes (Mincă et al., 2013; Rosa et al., 2019; Carter et al., 2021; Kim et al., 2021; McKay and Walker, 2021; Turk et al., 2021).

From our results, it was possible to show how phenomena treated through different models can be analyzed in terms of assumed directions and dependencies. Both in terms of defense mechanism and mood states, it was possible to highlight how mature defenses intervene in mood states to manage internal/external stressors deriving from clinical settings and 
practice. With particular reference to mood states, euthymia appeared significantly directed in the same direction of mature defensive processes.

This fact highlights a strong continuity with classical models and current empirical research on defense mechanisms, extended to the other main direction related to consciousness and coping. Our results suggested being compliant with current research, involving instruments of recent development, adherent to confirming previous speculative research through objective methods. Finally, the possibility offered by empirical research in our perspective represents the link between previous research and current needs to import, discuss, confirm, and possibly disconfirm data steamed from historical periods in which, from the beginning, the aim of reaching intersubjective validity was not neglected.

\section{IMPLICATIONS OF THE STUDY}

Current research in the clinical field presents the need to improve empirical studies, involving and exporting classical clinical themes into valid tools. This need can be extended to the role of defense mechanisms and the maintenance of stable mood so that the current study provided empirical research based on suppression and euthymia.

Through the use of recently validated instruments, high adaptive defense and euthymia have been examined in terms of correlations, differences, and dependencies. Through the performed analyses, several significant relations emerged, highlighting congruent directions, dependencies, and differences useful to understand the role of suppression regarding mood.

According to the used instruments, the emerged results would serve as a previous basis useful to extend the results on other samples to confirm and discuss further developments. The aim to detect existent relations must be extended to further samples and clinical conditions, close to the aim of deepening defenses' impact on mood stability. The emerged results were strictly related to clinical psychological dynamics, highlighting how the use of mature defense assumed coherent directions with mood balance and well-being, beside specific gender differences. In clinical psychological terms, these data represent relevant information, useful to understand how conscious phenomena bring the subjects closer to adaptive dynamics. In particular, a clear reference to satisfaction emerged, demonstrating the adaptive role of certain defenses in increasing assistance quality and efficacy.

\section{REFERENCES}

Bech, P. (2012). Clinical psychometrics, URL: https://onlinelibrary.wiley.com/doi/ book/10.1002/9781118511800.

Berney, S., de Roten, Y., Beretta, V., Kramer, U., and Despland, J. N. (2014). Identifying psychotic defenses in a clinical interview. J. Clin. Psychol. 70, 428-439. doi: 10.1037/0003-066X.55.1.89

Bond, M., Gardner, S. T., Christian, J., and Sigal, J. J. (1983). Empirical study of self-rated defense styles. Arch. Gener. Psych. 40, 333-338. doi: 10.1001/archpsyc. 1983.01790030103013

\section{LIMITATIONS AND CONCLUSION}

The present study has several limitations highlighting the need to support the emerged results through further research. The considered subjects were involved in clinical settings, so it would be necessary to extend the number of participants to better reflect the population. Despite the emergence of significant relations, the data should be extended and compared with more extended samples.

Moreover, the number of female subjects was higher than males. This fact recalls the need to reach a gender sample balance useful to better compare groups. The participants' age ranged from 25 and 30 years old, suggesting the purpose to include other age groups.

Although these references constitute limitations, the study was aimed at improving knowledge about the considered phenomena. This cross-sectional study can be regarded as an example of a knowledge extension on the themes mentioned earlier and clinical issues.

\section{DATA AVAILABILITY STATEMENT}

The raw data supporting the conclusions of this article will be made available by the authors, without undue reservation.

\section{ETHICS STATEMENT}

The studies involving human participants were reviewed and approved by Ethical Committee, Department of Cognitive Sciences, Psychology, Educational and Cultural Studies (COSPECS), University of Messina, Italy. The patients/participants provided their written informed consent to participate in this study.

\section{AUTHOR CONTRIBUTIONS}

EM made a significant contribution to design the research study, administer the protocol, draft the manuscript, revise it critically, perform the statistical analysis, and provide data interpretation. IM and AS made a significant contribution to design and revise the research study, and SS gave the final approval. All authors listed have made a substantial, direct and intellectual contribution to the work, and approved it for publication.

Brockman, R., Ciarrochi, J., Parker, P., and Kashdan, T. (2017). Emotion regulation strategies in daily life: mindfulness, cognitive reappraisal and emotion suppression. Cogn. Behav. Ther. 46, 91-113. doi: 10.1080/16506073. 2016.1218926

Bush, M. (1969). Psychoanalysis and scientific creativity: with special reference to regression in the service of the ego. J. Am. Psych. Assoc. 17, 136-190. doi: 10.1177/000306516901700108

Carrozzino, D., Svicher, A., Patierno, C., Berrocal, C., and Cosci, F. (2019). The euthymia scale: a clinimetric analysis. Psychother. Psychosom. 88, 119-122. doi: $10.1159 / 000496230$ 
Carter, A., Gilbert, P., and Kirby, J. N. (2021). Compassion-focused therapy for body weight shame: a mixed methods pilot trial. Clin. Psychol. Psychother. 28, 93-108. doi: 10.1002/cpp.2488

Catalano, A., Martino, G., Bellone, F., Papalia, M., Lasco, C., Basile, G., et al. (2019). Neuropsychological assessment in elderly men with benign prostatic hyperplasia treated with dutasteride. Clin. Drug Invest. 39, 97-102. doi: 10.1007/ s40261-018-0720-7

Compas, B. E., Jaser, S. S., Bettis, A. H., Watson, K. H., Gruhn, M. A., Dunbar, J. P., et al. (2017). Coping, emotion regulation, and psychopathology in childhood and adolescence: a meta-analysis and narrative review. Psychol. Bull. 143:939. doi: $10.1037 /$ bul0000110

Conversano, C. (2019). Common psychological factors in chronic diseases. Front. Psychol. 10:2727. doi: 10.3389/fpsyg.2019.02727

Conversano, C., Ciacchini, R., Orrù, G., Di Giuseppe, M., Gemignani, A., and Poli, A. (2020a). Mindfulness, Compassion, and Self-Compassion Among Health Care Professionals: what's New? A Systematic Review. Front. Psychol. 11:1683. doi: $10.3389 /$ fpsyg.2020.01683

Conversano, C., Di Giuseppe, M., Miccoli, M., Ciacchini, R., Di Silvestre, A., Lo Sterzo, R., et al. (2020b). Retrospective Analyses of Psychological Distress and Defense Style Among Cancer Patients. Clin. Neuropsych. 17, 217-224. doi: 10.36131/cnfioritieditore20200403

Conversano, C., and Di Giuseppe, M. (2021). Psychological Factors as Determinants of Chronic Conditions: clinical and Psychodynamic Advances. Front. Psychol. 12:635708. doi: 10.3389/fpsyg.2021.635708

Cramer, P. (2000). Defense mechanisms in psychology today: further processes for adaptation. Am. Psychol. 55:637. doi: 10.1037/0003-066X.55.6.637

De Burge, A. (2001). La levèè de la suppression en psicosomatiquè. Rev. Fr. Psychanal. 1, 11-27. doi: 10.3917/rfp.651.0011

Di Giuseppe, M., Di Silvestre, A., Lo Sterzo, R., Hitchcott, P., Gemignani, A., and Conversano, C. (2019). Qualitative and quantitative analysis of the defensive profile in breast cancer women: a pilot study. Health Psychol. Open 6:2055102919854667. doi: 10.1177/2055102919854667

Di Giuseppe, M., Miniati, M., Miccoli, M., Ciacchini, R., Orrù, R., Lo Sterzo, R., et al. (2020a). Defensive responses to stressful life events associated with cancer diagnosis. Med. J. Clin. Psychol. 8:20. doi: 10.6092/2282-1619/mjcp- 2384

Di Giuseppe, M., Perry, J. C., Lucchesi, M., Michelini, M., Vitiello, S., Piantanida, A., et al. (2020b). Preliminary reliability and validity of the DMRS-SR-30, a novel self-report measure based on the Defense Mechanisms Rating Scales. Front. Psych. 11:870. doi: 10.3389/fpsyt.2020.00870

Di Riso, D., Gennaro, A., and Salcuni, S. (2015). Defensive mechanisms and personality structure in an early adolescent boy: process and outcome issues in a non-intensive psychoanalytically oriented psychotherapy. Res. Psychother. 18, 114-128. doi: 10.4081/ripppo.2015.176

Eglinton, R., and Chung, M. C. (2011). The relationship between posttraumatic stress disorder, illness cognitions, defence styles, fatigue severity and psychological wellbeing in chronic fatigue syndrome. Psych. Res. 188, 245-252. doi: 10.1016/j.psychres.2011.04.012

Farma, T., and Cortinovis, I. (2000). Misurare i meccanismi di diffesa attraverso il" Defense Style Questionnaire" a 40 item. Attendibilita'dello strumento e suo utilizzo nel contesto Italiano. Ric. Psicol. 24, 127-144.

Fava, G. A., and Bech, P. (2016). The concept of euthymia. Psychother. Psychos. 85, 1-5. doi: 10.1159/000441244

Fava, G. A., Cosci, F., Guidi, J., and Tomba, E. (2017). Wellbeing therapy in depression: new insights into the role of psychological wellbeing in the clinical process. Depr. Anxiety 34, 801-808. doi: 10.1002/da.22629

Fiegl, S., Lahmann, C., O’Rourke, T., Probst, T., and Pieh, C. (2019). Depression according to ICD-10 clinical interview vs. depression according to the Epidemiologic Studies Depression Scale to predict pain therapy outcomes. Front. Psychol. 10:1862. doi: 10.3389/fpsyg.2019.01862

Fitzgerald, E. T. (1966). Measurement of openness to experience: a study of regression in the service of the ego. J. Person. Soc. Psychol. 4, 655-663. doi: $10.1037 / \mathrm{h} 0023980$

Freud, A. (1936). The ego and the defense mechanisms. Writings 2, 1-176.

Gangemi, A., Caprì, T., Fabio, R. A., Puggioni, P., Falzone, A. M., and Martino, G. (2018). Transcranial direct current stimulation (tdcs) and cognitive empowerment for the functional recovery of diseases with chronic impairment and genetic etiopathogenesis. Adv. Genet. Res. 18, 179-196.
Gugliandolo, M. C., Costa, S., Cuzzocrea, F., Larcan, R., and Martino, G. (2020). Adolescents and Body Uneasiness: the Contribution of Supportive Parenting and Trait Emotional Intelligence. J. Child Fam. Stud. 29, 2453-2462. doi: 10. 1007/s10826-020-01779-1

Guidi, J., and Fava, G. A. (2020). The emerging role of euthymia in psychotherapy research and practice. Clin. Psychol. Rev. 82:101941. doi: 10.1016/j.cpr.2020. 101941

Guidi, J., and Fava, G. A. (2021). Conceptual and Clinical Innovations of Wellbeing Therapy. Int. J. Cogn. Ther. 14, 196-208. doi: 10.1007/s41811-02100101-1

Hall, T., Krahn, G. L., Horner-Johnson, W., and Lamb, G. (2011). Examining functional content in widely used Health-Related Quality of Life scales. Rehabil. Psychol. 56:94. doi: 10.1037/a0023054

Ivicic, R., and Motta, R. (2017). Variables associated with secondary traumatic stress among mental health professionals. Traumatology 23, 196-204. doi: 10. $1037 /$ trm0000065

Jahoda, M. (1958). Current Concepts of Positive Mental Health. New York: Basic Books.

Kelly, R. R., McDonald, L. T., Jensen, N. R., Sidles, S. J., and LaRue, A. C. (2019). Impacts of psychological stress on osteoporosis: clinical implications and treatment interactions. Front. Psych. 10:200. doi: 10.3389/fpsyt.2019.00200

Kim, J. J., Oldham, M., Fernando, A. T., and Kirby, J. N. (2021). Compassion Mediates Poor Sleep Quality and Mental Health Outcomes. Mindfulness 12, 1252-1261. doi: 10.1007/s12671-021-01595-8

Kinsella, E. A., Smith, K., Bhanji, S., Shepley, R., Modor, A., and Bertrim, A. (2020). Mindfulness in allied health and social care professional education: a scoping review. Disab. Rehabil. 42, 283-295. doi: 10.1080/09638288.2018.1496150

Knafo, D. (2002). Revisiting Ernst Kris's concept of Regression in the service of the ego in art. Psychoanalytic Psychol. 19:24. doi: 10.1037/0736-9735.19.1.24

Kris, E., and Kaplan, A. (1952). Aesthetic ambiguity. In Psychoanalytic explorations in art. New York: International Universities Press, 243-264.

Kris, E. (1952a). Approaches to art. In Psychoanalytic explorations in art. New York: International Universities Press, 13-63.

Kris, E. (1952b). The psychology of caricature. In Psychoanalytic explorations in art. New York: International Universities Press, 173-188.

Kris, E. (1952c). Psychoanalytic explorations in art. New York: International Universities Press.

Lingiardi, V., Gazzillo, F., Colli, A., De Bei, F., Tanzilli, A., Di Giuseppe, M., et al. (2010). Diagnosis and assessment of personality, therapeutic alliance and clinical exchange in psychotherapy research. Res. Psychother. 2, 97-124. doi: 10.4081 /ripppo. 2010.36

Lomas, T., Medina, J. C., Ivtzan, I., Rupprecht, S., and Eiroa-Orosa, F. J. (2019). Mindfulness-based interventions in the workplace: An inclusive systematic review and meta-analysis of their impact upon wellbeing. J. Posit. Psychol. 14, 625-640. doi: 10.1080/17439760.2018.1519588

Martino, G., Caputo, A., Schwarz, P., Bellone, F., Fries, W., Quattropani, M. C., et al. (2020c). Alexithymia and inflammatory bowel disease: a systematic review. Front. Psychol. 11:1763. doi: 10.3389/fpsyg.2020.01763

Martino, G., Caputo, A., Vicario, C. M., Catalano, A., Schwarz, P., and Quattropani, M. C. (2020b). The relationship between alexithymia and type 2 diabetes: a systematic review. Front. Psychol. 11:2026. doi: 10.3389/fpsyg.2020.02026

Martino, G., Catalano, A., Agostino, R. M., Bellone, F., Morabito, N., Lasco, C. G., et al. (2020a). Quality of life and psychological functioning in postmenopausal women undergoing aromatase inhibitor treatment for early breast cancer. PLoS One 15:e0230681. doi: 10.1371/journal.pone.0230681

Martino, G., Sardella, A., Bellone, F., Lasco, C., Langher, V., Cazzato, V., et al. (2019). Executive functions and bone health: a focus on cognitive impulsivity and bone mineral density. Mediter. J. Clin. Psychol. 7:2167. doi: 10.6092/22821619/2019.7.2167

McKay, T., and Walker, B. R. (2021). Mindfulness, self-compassion and wellbeing. Person. Indiv. Diff. 168:110412. doi: 10.1016/j.paid.2020.110412

McNally, P. J., Charlton, R., Ratnapalan, M., and Dambha-Miller, H. (2019). Empathy, transference and compassion. J. Roy. Soc. Med. 112, 420-423. doi: $10.1177 / 0141076819875112$

Merlo, E., Sicari, F., Frisone, F., Costa, G., Alibrandi, A., Avena, G., et al. (2021). Uncertainty, alexithymia, suppression and vulnerability during the COVID-19 pandemic in Italy. Health Psychol. Rep. 9:104078. doi: 10.5114/hpr.2021.104078 
Merlo, E. M. (2019). Opinion Article: The role of psychological features in chronic diseases, advancements and perspectives. Mediter. J. Clin. Psychol. 7:607783. doi: 10.6092/2282-1619/2019.7.2341

Merlo, E. M., Sicari, F., Frisone, F., Alibrandi, A., and Settineri, S. (2020a). Personality types and dreaming in future health professionals: Effect of age and gender. Int. J. Dream Res. 13, 160-172. doi: 10.11588/ijodr.2020.2.70571

Merlo, E. M., Stoian, A. P., Motofei, I. G., and Settineri, S. (2020b). Clinical Psychological Figures in Healthcare Professionals: Resilience and Maladjustment as the "Cost of Care". Front. Psychol. 11:607783. doi: 10.3389/ fpsyg.2020.607783

Metzger, J. A. (2014). Adaptive defense mechanisms: function and transcendence. J. Clin. Psychol. 70, 478-488. doi: 10.1002/jclp.22091

Mincă, D. G., Furtunescu, F., Calinoiu, G., Domnariu, C., and Costea, R. (2013). Profile of persons involved in traffic accidents in Romania. Rom. J. Leg. Med. 21, 155-160. doi: 10.4323/rjlm.2013.155

Palestrini, L., Prati, G., Pietrantoni, L., and Cicognani, E. (2009). La qualità della vita professionale nel lavoro di soccorso: Un contributo alla validazione italiana della Professional Quality of Life Scale (ProQOL). Psicoter. Cogn. Comport. 15, 205-227.

Perry, J. C. (1990). Defense Mechanism Rating Scale. Cambridge, MA: Harvard School of Medicine Publ.

Perry, J. C., and Bond, M. (2012). Change in defense mechanisms during long-term dynamic psychotherapy and five-years outcome. Am. J. Psych. 169, 916-925. doi: 10.1176/appi.ajp.2012.11091403

Perry, J. C., and Henry, M. (2004). "Studying defense mechanisms in psychotherapy using the Defense Mechanism Rating Scales," in Advances in psychology,136. Defense mechanisms: Theoretical, research and clinical perspectives, eds U. Hentschel, G. Smith, J. G. Draguns, and W. Ehlers, (Amsterdam: Elsevier), 165-192. doi: 10.1016/S0166-4115(04)80034-7

Perry, J. C., Metzger, J., and Sigal, J. J. (2015). Defensive Functioning Among Women With Breast Cancer and Matched Community Controls. Psychiatry 78, 156-169. doi: 10.1080/00332747.2015.1051445

Porcerelli, J. H., Cramer, P., Porcerelli, D. J., and Arterbery, V. E. (2017). Defense Mechanisms and Utilization in Cancer Patients Undergoing Radiation Therapy. A Pilot Study. J. Nerv. Ment. Dis. 205, 466-470. doi: 10.1097/NMD. 0000000000000674

Rosa, V., Tomai, M., Lauriola, M., and Martino, G. (2019). Body mass index, personality traits, and body image in Italian pre-adolescents: An opportunity for overweight prevention. Psihologija 52, 379-393. doi: 10.2298/PSI181121009R

Schäfer, J. Ö, Naumann, E., Holmes, E. A., Tuschen-Caffier, B., and Samson, A. C. (2017). Emotion regulation strategies in depressive and anxiety symptoms in youth: A meta-analytic review. J. Youth Adolesc. 46, 261-276. doi: 10.1007/ s10964-016-0585-0

Settineri, S., Frisone, F., Alibrandi, A., and Merlo, E. M. (2019a). Emotional suppression and oneiric expression in psychosomatic disorders: early manifestations in emerging adulthood and young patients. Front. Psychol. 10:1897. doi: 10.3389/fpsyg.2019.01897

Settineri, S., Merlo, E. M., Frisone, F., Alibrandi, A., Carrozzino, D., Diaconu, C. C., et al. (2019b). Suppression Mental Questionnaire App: a mobile web servicebased application for automated real-time evaluation of adolescent and adult suppression. Mediter. J. Clin. Psychol. 7:2056. doi: 10.6092/2282-1619/2019.7. 2056

Singh, J., Karanika-Murray, M., Baguley, T., and Hudson, J. (2020). A Systematic Review of Job Demands and Resources Associated with Compassion Fatigue in Mental Health Professionals. Int. J. Environ. Res. Publ. Health 17:6987. doi: 10.3390/ijerph17196987

Stamm, B. H. (2005). The ProQOL manual: The professional quality of life scale: Compassion satisfaction, burnout \& compassion fatigue/secondary trauma scales. Baltimore, MD: Sidran.

Stamm, B. H. (2009). Professional quality of life: Compassion satisfaction and fatigue version 5 (ProQOL). Baltimore, MD: Sidran.

Szwec, G. (2018). "The capacity to say no and psychosomatic disorders in childhood," in Psychosomatics Today, eds M. Aisenstein, and E. R. de Aisemberg, (Abingdon: Routledge), 163-179. doi: 10.4324/978042947 9229-9

Topp, C. W., Østergaard, S. D., Søndergaard, S., and Bech, P. (2015). The WHO-5 Well-Being Index: a systematic review of the literature. Psychother. Psychos. 84, 167-176. doi: 10.1159/000376585

Turk, F., Kellett, S., and Waller, G. (2021). Determining the potential links of selfcompassion with eating pathology and body image among women and men: A cross-sectional mediational study. Body Image 37, 28-37. doi: 10.1016/j.bodyim. 2021.01.007

Vaillant, G. E. (1977). Adaptation to life. Abingdon: Routledge.

Vaillant, G. E. (1992). Ego Mechanisms of Defense: A Guide for Clinicians and Researchers. Philadelphia: American Psychiatric Association.

Vaillant, G. E. (1994). Ego mechanisms of defense and personality psychopathology. J. Abnor. Psychol. 103:44.

Vita, R., Caputo, A., Quattropani, M. C., Watt, T., Feldt-Rasmussen, U., Puleio, P., et al. (2020). Quality of Life in Patients with Hyperthyroidism: Where do we stand? Mediter. J. Clin. Psychol. 8, 1-28. doi: 10.6092/2282-1619/mjcp2521

Warnes, H. (1982). The dream specimen in psychosomatic medicine in the light of clinical observations. Psychother. Psychos. 38, 154-164. doi: 10.1159/000287623

Weissman, D. G., Bitran, D., Miller, A. B., Schaefer, J. D., Sheridan, M. A., and McLaughlin, K. A. (2019). Difficulties with emotion regulation as a transdiagnostic mechanism linking child maltreatment with the emergence of psychopathology. Devel. Psychopathol. 31:899. doi: 10.1017/ S0954579419000348

Wild, C. (1965). Creativity and adaptive regression. J. Person. Soc. Psychol. 2, 161-169. doi: 10.1037/h0022404

World Health Organization (WHO), (1998). Wellbeing Measures in Primary Health Care/the DEPCARE Project: Report on a WHO Meeting, STOCKHOLM, Sweden 12-13 February 1998. Geneva: World Health Organization.

Zeidner, M., Hadar, D., Matthews, G., and Roberts, R. D. (2013). Personal factors related to compassion fatigue in health professionals. Anx. Stress Coping 26, 595-609. doi: 10.1080/10615806.2013.777045

Conflict of Interest: The authors declare that the research was conducted in the absence of any commercial or financial relationships that could be construed as a potential conflict of interest.

Copyright (c) 2021 Merlo, Stoian, Motofei and Settineri. This is an open-access article distributed under the terms of the Creative Commons Attribution License (CC BY). The use, distribution or reproduction in other forums is permitted, provided the original author(s) and the copyright owner(s) are credited and that the original publication in this journal is cited, in accordance with accepted academic practice. No use, distribution or reproduction is permitted which does not comply with these terms. 